\title{
Usability analysis of on-line educational courses on the platform "Higher school mathematics teacher"
}

\author{
Kateryna Vlasenko ${ }^{1, *}$, Sergii Volkov², Iryna Sitak $^{2}$, Iryna Lovianova ${ }^{3}$, and Dmytro Bobyliev ${ }^{3}$ \\ ${ }^{1}$ Donbas State Engineering Academy, 7 Academic Str., Kramatorsk, 84313, Ukraine \\ ${ }^{2}$ The Institute of Chemical Technologies (the town of Rubizhne) of the East Ukrainian Volodymyr Dahl National University, \\ 31 Volodymyrska Str., Rubizhne, 93009, Ukraine \\ ${ }^{3}$ Kryvyi Rih State Pedagogical University, 54 Gagarina Ave., Kryvyi Rih, 50086, Ukraine
}

\begin{abstract}
The article addresses the issue of implementing the usability principles of educational internet resources. The paper debates the latest researches on the question concerning the search for the factors that influence the results of online education. The analysis, which we carried out, allowed us to focus on such known six criteria of usability design as Information Quality, System Navigation, System Learnability, Visual Design, Instructional Assessment, and System Interactivity and suggest the existence of the seventh criterion named Responsiveness. The research considers the principles of usability implementation following the example of the open platform of online education "Higher School Mathematics Teacher". The answers given by 203 respondents during the survey allowed defining the direction of implementing the usability criteria on the platform. We were eager to know the opinion of teachers and students, who became the first users of the platform. The article discusses the criteria implementation while developing online courses on the platform. There was ground to conclude that when designing on-line platform courses, all seven usability subcategories are important.
\end{abstract}

\section{Introduction}

\subsection{Problem statement}

Developing on-line courses is one way to a sustainable future for our society through education. The modern market of online education offers a great number of online courses for educating adults, young people and children. The subject matter and complexity of such courses differ a lot, but certain development principles and operation of educational internet resources have a lot in common. One of the most important questions while developing any of the sites is its usability. This term is used as a measure of site friendliness, its understandability, and naturalness for the user. Web-site usability is determined by simplicity. Simplicity makes internet resources easy to perceive by users, makes it possible to carry out a fast shift to the necessary content and facilitates access to information. Therefore, the research of usability issues in educational software is an important aspect of developing distant education.

\subsection{Analysis of the latest researches and publications}

While searching for the factors that influence the results of online education, scientists paid attention to the interface of educational platforms. J. Nielsen [1] was one of the first scientists who used the term usability. He developed a heuristic evaluation - methodology of researching the software usability. So-called "Nielsen protocol" consists of ten heuristics developed for the software:

- The user can detect the system status;

- The system uses the terminology, which is convenient for the user;

- Free system manageability, support of removal function (undo) and repetition function (redo);

- Consistency and standards;

- Error prevention and warning the user about further problems;

- Load minimization on the user's memory;

- Flexibility and efficiency of the usage;

- Aesthetic and minimal design;

- The system has to offer the user a constructive solution to the issues that arise;

- Presence of reference information in the system.

$\mathrm{T}$. Reeves et al [2] increased the number of heuristics up to fifteen when they developed them specifically for electronic education. While designing the systems of electronic education, the scientists S. C. Srivastava et al [3] proved that the attention should be focused on the learning outcomes and not only on satisfying users' interests. The interface has to be attractive and simple to use, but its main task is to give possibilities to the user to build his/her own strategy of education. D. Squiresa and J. Preece [4] offered an approach that integrates the idea

\footnotetext{
* Corresponding author: vlasenkokv@ukr.net
} 
of heuristics of software usability with the idea of considering the educational results and issues. In scientists' opinion, the main criterion of developing electronic education has to become its reliability. M. Asarbakhsh and J. Sandars [5] named the usefulness of technologies and their usability among the significant factors that should be considered while developing and implementing technologies of online education.

While highlighting and describing six criteria of usability design, A. Alshehri et al [6] formulated and carried out the research of these criteria concerning their importance for students:

1) Information Quality (IQ),

2) System Navigation (SN),

3) System Learnability (SL),

4) Visual Design (VD),

5) Instructional Assessment (IA),

6) System Interactivity (SI).

While ascertaining if this list of criteria could be considered full taking into account the possibility to use mobile devices by users, we addressed the statistics data [7]. It is clear from the data that $58 \%$ of site visits were from mobile devices. $44 \%$ of users of mobile devices visited the sites of the category "Career and Education" and $42 \%$ visited the sites of the category "Science". Using the service Google Analytics [8] we detected that $35 \%$ of users of the platform "Higher School Mathematics Teacher" [9] also use mobile devices. So, while analyzing the statistics we can say that the pattern of growth of website visitors from mobile devices will be kept in the future. Taking this fact into account we considered it necessary to introduce an additional seventh criterion "usability design" for educational web systems called Responsiveness (RS) that would reflect usability for visitors from mobile devices. The relevance of this assumption was checked in the research results.

This article is aimed at analyzing the approaches of online courses developers to implement usability, showing usability implementation principles following the example of the open platform of online education "Higher School Mathematics Teacher".

\section{Methods}

We used the Inductive Content Analysis Method during the research. With its help, we carried out the analysis of the structure and principles of constructing the most popular world and domestic systems of online education by highlighting seven parameters of educational platform usability. These parameters were included in the survey of higher school teachers and students. The survey was aimed at getting the evaluation by respondents concerning the usability and simplicity of online courses on educational platforms that are used by the respondents. The survey was divided into two parts. In the first part, there were questions concerning the information about the respondents, such as sex, age, status (teacher, student), their experience of using online courses and educational platforms on which they took online courses, and the aim of online education. This information was gathered to get descriptive statistics of research selection and selection of educational online platforms for the analysis. The second part of the survey included the questions concerning relative importance (value) of the determined usability categories and subcategories and category ratings for users. This section included 35 elements divided into seven parts. We had to determine the category place from 1 to 7 depending on its impact on the platform usability (where 1 is the most important). Getting a smaller evaluation rate of the corresponding feature of usability demonstrates its greater importance for teachers and students during the online course. Subcategories have to be evaluated using a 3-point scale where "-1" affects the criterion, " 0 " does not affect the criterion at all, "+1" has a positive effect on the criterion.

The survey was held directly by tutors of the educational online platform "Higher School Mathematics Teacher" in higher schools. 246 participants took part in the survey, among them 85 teachers and 161 students of Donbas State Engineering Academy, Institute of chemical technologies of Dahl East Ukrainian National University (the town of Rubizhne), Kryvyi Rih State Pedagogical University, Donbas National Academy of Civil Engineering and Architecture. It must be said that 43 participants (18 teachers and 25 students who constituted $17,4 \%$ of the respondents) stated that they had never used online education. Therefore, the final number of respondents is 203 participants - 67 teachers and 136 students.

Research conclusions reached by K. Vlasenko et al [10], and the analysis of the results of teachers and students' survey allowed determining the direction of implementing usability criteria on the platform "Higher School Mathematics Teacher" [9]. First of all, we found out how we can implement the criterion Information Quality (IQ) that describes the information correspondence in the system to learners' needs and the criterion System Learnability (SL) that characterizes education simplicity and rapidity. The quality of these criteria depends on the tutor's competence that creates and supports the online course. In order to create high-quality content following the criteria IQ and SL, the tutors of the platform "Higher School Mathematics Teacher" [9] are given a possibility to use software tools to format the text, insert graphics, video- and audio information, insert links, formulas, tests, surveys. K. Vlasenko et al [11] described the application use during developing the educational online platform.

The criterion System Navigation reflects the quality of navigational tools. On the platform, it is formed with the help of main and additional menus that are posted at the top of the interface and are present on every page. Their presence allows the user to navigate to the necessary section. In order to provide a clear sequence, "breadcrumb" navigation is posted on the pages and allows representing visually the hierarchy of top-level pages and navigating all over them. The presence of such an element is especially important when there are a great number of pages that are put one in another. Ease of navigation is also provided by the presence of links directly in the content of the educational text.

The criterion Visual Design reflects the aesthetics of displaying the educational system. In order to ensure 
readability and aesthetic design the following basic color scheme in the RGB model coding was determined: light colors for the body (\#FFFFFF, \#F0EAEE), dark color for the main content (\#333333) and additional colors for structural elements for links (\#993333, \#B8999F, \#D6DDE3). The general structure of the platform interface includes header, footer, sidebar and content layout elements. This structure corresponds to the purpose of the platform information content. Typography was chosen in order to provide the text and it includes the text without any notches, particular style display for headings, subheadings, and the main text.

The criterion Instructional Assessment reflects the simplicity and efficiency of evaluation tools. This criterion is provided using feedback forms, subsystems of testing, survey and file downloading. Feedback forms are used both for educational and general questions.

The criterion System Interactivity reflects the presence of simple tools of interaction among participants of the educational process. In order to correspond to this criterion the forum of the platform users that ensures the interaction student-teacher, teacher-student, and studentstudent was implemented.

The criterion Responsiveness reflects the quality, aesthetics of system display on mobile devices that have different resolution. In order to ensure the adaptability of platform design, methods of the interface presentation using stylization CSS for particular separate capabilities of the devices are used. The elements of the menu and sidebar interface have a particular view on mobile devices. Text size, headings and subheadings, links, buttons, image size and other interface elements were adapted to correspond to this criterion.

Localization and customization are also important in order to implement usability. The adaptation of mass products on demand of a particular customer on the educational platform "Higher School Mathematics Teacher" takes place through partial content change following a particular request, additional staffing of the course with extra activities and materials. Platform tutors monitor regularly discussions concerning the courses on "Teachers' forum", react promptly to offers made by the users of the course. The development of new courses is also based on studying requests and wishes made by platform users.

\section{Results}

We offer to consider the division of respondents according to their age and sex in Table1.

Table 1. Division of respondents according to their age and sex.

\begin{tabular}{|l|c|c|c|c|c|c|}
\hline \multirow{2}{*}{ Characteristics } & \multicolumn{2}{|c|}{ Teachers } & \multicolumn{2}{c|}{ Students } & \multicolumn{2}{c|}{ Total } \\
\cline { 2 - 7 } & number & $\%$ & number & $\%$ & number & $\%$ \\
\hline sex & & & & & & \\
male respondents & 35 & 52,2 & 84 & 61,8 & 119 & 58,6 \\
female respondents & 32 & 48,8 & 52 & 38,2 & 84 & 41,4 \\
\hline age & & & & & & \\
under 30 & 3 & 4,5 & 136 & 100 & 139 & 68,5 \\
$31-50$ & 42 & 62,7 & 0 & 0 & 42 & 20,7 \\
over 50 & 22 & 32,8 & 0 & 0 & 22 & 10,8 \\
\hline
\end{tabular}

According to the survey results in Table 2, the majority of respondents $(70,9 \%)$ studied the online courses in higher schools developed with the help of the distant learning system Moodle. Furthermore, the respondents used the platforms Prometheus [12], EdEra [13], The Open University [14], Edx [15], Coursera [16], Intuit [17] for education (respondents had a possibility to name several educational resources). The aim of the education determined by the majority $(68,9 \%)$ was the current education; moreover, skills development $23,8 \%$, acquiring additional skills $-3,1 \%$, personal development $-4,2 \%$.

Table 2. Online platforms where respondents studied.

\begin{tabular}{|l|c|c|c|c|c|c|}
\hline \multirow{2}{*}{ Online platforms } & \multicolumn{2}{|c|}{ Teachers } & \multicolumn{2}{c|}{ Students } & \multicolumn{2}{c|}{ Total } \\
\cline { 2 - 7 } & number & $\%$ & number & $\%$ & number & $\%$ \\
\hline $\begin{array}{l}\text { Moodle-based } \\
\text { LMS }\end{array}$ & 14 & 20,9 & 130 & 95,6 & 144 & 70,9 \\
\hline Prometheus & 8 & 11,9 & 2 & 1,5 & 10 & 4,9 \\
\hline EdEra & 16 & 23,9 & - & - & 16 & 7,9 \\
\hline $\begin{array}{l}\text { The Open } \\
\text { University }\end{array}$ & 4 & 6,0 & 1 & 0,7 & 5 & 2,5 \\
\hline Edx & 4 & 6,0 & 2 & 1,5 & 6 & 3,0 \\
\hline Coursera & 18 & 26,9 & - & - & 18 & 8,9 \\
\hline Intuit & 7 & 10,5 & 5 & 3,7 & 12 & 5,9 \\
\hline Other platforms & 4 & 6,0 & 3 & 2,2 & 7 & 3,5 \\
\hline
\end{tabular}

We offer to consider the categories and subcategories from the other survey part. We have found out the importance of the defined categories and subcategories for users, their usability and rating.

Category 1 - Information Quality (IQ), subcategories:

1.1 Ease of navigation

1.2 Navigation support

1.3 Reference reliability

1.4 Understandability of action sequence

1.5 Ease of access

Category 2 - System Navigation (SN), subcategories:

2.1 Ease of education

2.2 Reference predictability

2.3 Education without any initial preparations

2.4 Formulation clarity

2.5 Sufficient online assistance

Category 3 - System

Learnability

(SL),

subcategories:

3.1 Readability

3.2 Design aesthetics

3.3 Layout information content

3.4. Presentation structure

3.5 General course consistency

Category 4 - Visual Design (VD), subcategories:

4.1. Information correctness

4.2. Information conformity

4.3 Information completeness

4.4. Ease of information understanding

4.5 Information timeliness

Category 5 - Instructional Assessment subcategories:

5.1 Evaluation tools efficiency

5.2 Ease of using evaluation tools

5.3 Reality of achieving learning objectives 
5.4 Accessibility for material understanding

5.5 Feedback Information content

Category 6 - System Interactivity (SI), subcategories:

6.1 Efficiency of communication tools

6.2 Implementation of communication between the tutor and student

6.3 Possibility of communication "student - student"

6.4 Interaction organization

6.5 Feedback speed

Category 7 - Responsiveness (RS), subcategories:

7.1 Flexible layouts (website layout that will dynamically resize to any width)

7.2 Flexible images (scalable images)

7.3 Flexible media (scalable images, video and other formats)

7.4 Flexible menu

7.5 Flexible navigation

The results of respondents' evaluation of usability criteria are provided in Table 3.

Table 3. Respondents' evaluation of online education systems according to Usability design criteria.

\begin{tabular}{|l|c|c|c|c|c|c|c|}
\hline \multirow{2}{*}{ Systems of online education } & \multicolumn{5}{|c|}{ Criteria } \\
\cline { 2 - 6 } & IQ & SN & SL & VD & IA & SI & RS \\
\hline Moodle-based LMS & 1,31 & 2,3 & 3,17 & 3,99 & 6,11 & 6,87 & 4,56 \\
\hline Prometheus & 1,18 & 1,87 & 2,95 & 4,02 & 5,89 & 6,76 & 4,81 \\
\hline EdEra & 1,04 & 2,12 & 3,01 & 3,68 & 6,03 & 6,94 & 5,12 \\
\hline The Open University & 1,24 & 1,97 & 2,76 & 4,17 & 5,84 & 6,63 & 5,26 \\
\hline Edx & 1,11 & 2,07 & 3,24 & 4,31 & 6,24 & 6,80 & 5,08 \\
\hline Coursera & 2,13 & 3,14 & 1,05 & 3,79 & 5,26 & 6,48 & 4,74 \\
\hline Intuit & 2,41 & 1,27 & 3,15 & 4,02 & 4,87 & 6,81 & 4,86 \\
\hline
\end{tabular}

The results analysis helped us to confirm the assumption about the necessity to consider one more criterion. The respondents recognized the greater importance of the criterion Responsiveness rather than the criteria Instructional Assessment and System Interactivity.

We offer to consider the evaluation results of the importance of usability subcategory in Table 4.

Table 4. Respondents' evaluation of the importance of usability subcategory.

\begin{tabular}{|l|c|}
\hline \multicolumn{1}{|c|}{ Usability subcategories } & $\begin{array}{c}\text { Average } \\
\text { estimate }\end{array}$ \\
\hline 1.1. Ease of navigation & 0,91 \\
1.2 Navigation support & 0,72 \\
1.3 Reference reliability & 0,64 \\
1.4 Understandability of sequence of actions & 0,78 \\
1.5 Ease of getting access & 0,81 \\
\hline 2.1. Ease of education & 0,88 \\
2.2 Reference predictability & 0,42 \\
2.3 Education without any initial preparations & 0,56 \\
2.4 Formulation clarity & 0,71 \\
2.5 Sufficient online assistance & 0,65 \\
\hline 3.1 Readability & 0,57 \\
3.2 Design aesthetics & 0,74 \\
3.3 Layout information content & 0,63 \\
3.4 Presentation structure & 0,59 \\
3.5 General course consistency & 0,47 \\
\hline 4.1 Information correctness & 0,81 \\
4.2 Information conformity & 0,67 \\
4.3 Information completeness & 0,52 \\
\hline
\end{tabular}

\begin{tabular}{|l|c|}
\hline \multicolumn{1}{|c|}{ Usability subcategories } & $\begin{array}{c}\text { Average } \\
\text { estimate }\end{array}$ \\
\hline 4.4 Ease of information understanding & 0,87 \\
4.5 Information timeliness & 0,62 \\
\hline 5.1 Evaluation tools efficiency & 0,42 \\
5.2 Ease of using evaluation tools & 0,37 \\
5.3 Reality of achieving learning objectives & 0,93 \\
5.4 Accessibility for material understanding & 0,86 \\
5.5 Feedback information content & 0,72 \\
\hline 6.1 Efficiency of communication tools & 0,62 \\
6.2 Implementation of communication between & 0,71 \\
the tutor and student & \\
6.3 Possibility of communication "student - & 0,69 \\
student" & \\
6.4 Interaction organization & 0,53 \\
6.5 Feedback speed & 0,74 \\
\hline 7.1. Layout flexibility & 0,85 \\
7.2. Image scaling & 0,78 \\
7.3. Media scaling & 0,81 \\
7.4. Menu flexibility & 0,67 \\
7.5. Navigation flexibility & 0,91 \\
\hline
\end{tabular}

According to the results, we can conclude that all the usability subcategories are important because any of them has a negative average rating.

\section{Discussion}

While researching the usability of educational platforms, scientists marked site usability as an important element of developing educational platforms.

Inductive Content Analysis Method helped to determine the direction of implementing usability criteria on the platform "Higher School Mathematics Teacher". We agree with the scientists A. Alshehri et al [6] that the most important criterion of usability design is Information Quality that describes the correspondence of the information in the system to learners' needs. We have also considered Y. Nilsen's and H. Loranger's point of view [18] who point out that the efficiency of any application work and its attractiveness for the user depend on search engine and navigation, downloading speed, menu design. In the authors' opinion the focus on the user, their needs and requests have to be principal. This idea is agreed with the conclusion provided by V. Hodakov and O. Boskin [19] in which they believe that the adaptive user interface is the main criterion of computer system attractiveness. Such interface reflects the capability of a simple software product or a complicated program technical complex to adapt to the user's needs, consider their psychophysical characteristics and abilities, dynamic change, support the consolidation of common actions to solve the given task.

The ranking results are presented in the diagram (Fig. 1).

While analyzing categories and subcategories we paid attention to the research by L.P. Dringus and M. S. Cohen [20] who defined 13 heuristic categories that influence the usability of the educational environment on the Internet. They include visibility, functionality, aesthetics, feedback and assistance, mistakes prevention, memory, course management, interactivity, flexibility, consistency, efficiency, mitigation, contraction, and accessibility. While researching the criteria of evaluating 
the usability of the electronic education system, X. Fang and C. W. Holsapple [21] highlighted system navigation, performance system, visual design, information quality, instructive evaluation, and system interactivity. Following the results of their research, information quality is the most important criterion; navigation in the system of electronic education takes second place. Instructive evaluation and system interactivity are the least important design categories that influence the usability evaluation of the electronic education system. In order to consider the concept of the platform "Higher School Mathematics Teacher" [9], according to which we have to take into account the wish of different age audience of online courses, we followed the recommendations by L. Hasan [22] who studied the usability of educational websites from university students' perspective. The scientist defined that the content and navigation are the first and second desirable design categories that have to be considered during the usability evaluation of websites for educational programs while organization and architecture are the least important categories.

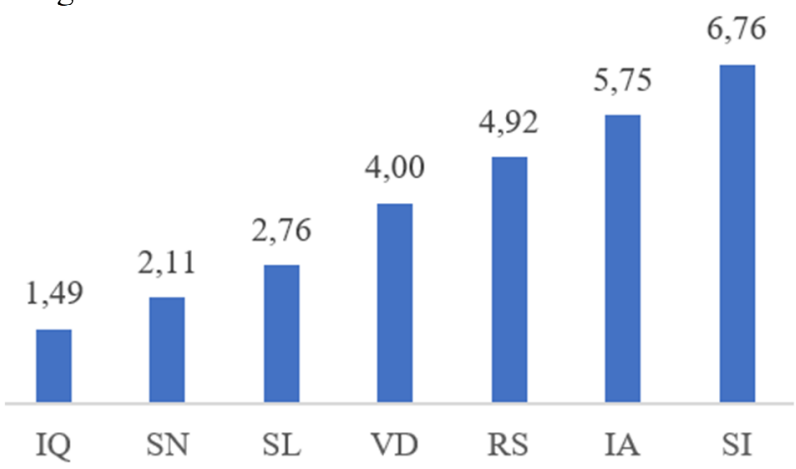

Fig. 1. The distribution of places categories from 1st to 7 th depending on their impact on the usability of the platform (where 1 is the most important).

\section{Conclusions}

The actuality of researching the usability issue in educational software as a direction of developing distant education arises from the growth of the modern Internet education market. This implies particular requirements concerning the usability of online courses.

The Inductive Content Analysis Method helped us review the existing papers concerning the criterial basis of usability design. This method also helped to define the actual usability criteria of the educational platform as well as to provide an assumption about the necessity to consider the criterion driven by the presence and active usage of mobile devices.

In order to clarify the hypothesis, we developed a survey for teachers and students who are online course users. The analysis of survey results was held in two directions: to get descriptive statistics of online course users and study the relative importance of evaluating categories of educational platform usability. Such an approach to the survey allowed getting substantial information concerning the preferences of online course users that should be taken into consideration during its development.

Therefore, according to the research results, we found out that it is worthwhile to add the criterion Responsiveness that reflects the usability of mobile devices for online education. So, according to the results of researches and surveys, we offer the next order of usability criteria in descending order:

1) Information Quality (IQ),

2) System Navigation ( $\mathrm{SN})$,

3) System Learnability (SL),

4) Visual Design (VD),

5) Responsiveness (RS),

6) Instructional Assessment (IA),

7) System Interactivity (SI).

Further research will be aimed at the usability criteria analysis of the educational online platform "Higher School Mathematics Teacher".

\section{Reference}

1. J. Nielsen, Usability engineering (Academic Press, New York, 1993)

2. T. Reeves, L. Benson, D. Elliot, M. Grant, D. Holschuh, B. Kim, H. Kim, E. Lauber, S. Loh, Usability and Instructional Design Heuristics for ELearning Evaluation, in proceedings of World, in Conference on Educational Multimedia, Hypermedia \& Telecommunications (ED-MEDIA 2002), vol. 1, pp. 1615-1621

3. S. C. Srivastava, S. Chandra, H.M. Lam, Usability Evaluation of E-Learning Systems, in Encyclopedia of Information Science, ed. by M. Khosrow-Pour (2009), pp. 3897-3993

4. D. Squires, J. Preece, Predicting quality in educational software: Evaluating for learning, usability and the synergy between them. Interacting with Computers 11(5), 467-483 (1999)

5. M. Asarbakhsh, J. Sandars, E-learning: the essential usability perspective. Clinical Teacher 10(1), 47-50 (2013)

6. A. Alshehri, M. Rutter, S. Smith, Assessing the Relative Importance of an E-learning system's Usability Design Characteristics Based on Students' Preferences. Eur. J. of Educational Research 8(3), 839-855 (2019)

7. E. Enge, Mobile vs. Desktop usage in 2019 (Perficient, Inc. 2019), https:/www.perficientdigital.com/insights/ourresearch/mobile-vs-desktop-usage-study. Accessed 5 Oct. 2019

8. Google Analytics (2019), https://analytics.google.com/analytics/web/\#/reporthome/a79926449w134033336p138081558. Accessed 12 Oct 2019

9. Educational Online Platform "Higher School Mathematics Teacher" (2019), http://formathematics.com. Accessed 11 Oct 2019 
10. K. Vlasenko, I. Lovianova, I. Sitak, O. Chumak, O. Kondratyeva, Training of Mathematical Disciplines Teachers for Higher Educational Institutions as a Contemporary Problem. Universal J. of Educational Research 7(9), 1892-1900 (2019)

11. K. Vlasenko, S. Volkov, D. Kovalenko, I. Sitak et al, Web-based online-course training higher school mathematics teachers. CEUR Workshop Proceedings (2020, in press)

12. Prometheus (2019), https://prometheus.org.ua/. Accessed 11 Sep 2019

13. Studio of online education Educational Era (2019), https://www.ed-era.com/. Accessed 28 Sep 2019

14. The Open University (2019), http://www.open.ac.uk. Accessed 08 Sep 2019

15. Edx (2019), https://www.edx.org/. Accessed 28 Nov 2019

16. Coursera (2019), https://www.coursera.org/. Accessed 03 Nov 2019

17. National open university "Intuit" (2019), https://www.intuit.ru/. Accessed 29 Nov 2019

18. J. Nielsen, H. Loranger, Prioritizing Web Usability (New Riders, San Francisco, 2006)

19. V.E. Hodakov, O.O. Boskin, Interface as an integral component of the computer system. Problems of information technologies 22, 128-133 (2017)

20. L.P. Dringus, M.S. Cohen, An adaptable usability heuristic checklist for online courses, in Proceedings Frontiers in Education 35th Annual Conference, Oct. 20, 2005

21. X. Fang, C.W. Holsapple, An empirical study of web site navigation structures' impacts on web site usability. Decision Support Systems 43(2), 476-491 (2007)

22. L. Hasan, Evaluating the usability of educational websites based on students' preferences of design characteristics. Int. Arab J. of E-Technology 3(3), 179-193 (2014) 